ORIGINAL ARTICLE

\title{
Proliferating fibroblasts at the invading tumour edge of colorectal adenocarcinomas are associated with endogenous markers of hypoxia, acidity, and oxidative stress
}

\author{
E Sivridis, A Giatromanolaki, M I Koukourakis
}

J Clin Pathol 2005;58:1033-1038. doi: 10.1136/icp.2005.026260

See end of article for authors' affiliations .......

Correspondence to: Dr M I Koukourakis, Department of

Radiotherapy/Oncology, Democritus University of Thrace Medical School,

PO Box 12,

Alexandroupolis 68100, Greece; targ@her.forthnet. gr

Accepted for publication 24 March 2005

\begin{abstract}
Background: Stroma frequently forms at sites of active tumour invasion, and may be important for tumour growth and progression. The term "stromatogenesis" is used to describe this unique process that involves host peritumorous fibroblasts and is very different to reactive fibrosis.

Aims/Methods: To investigate the activation status of host fibroblasts at the invading tumour edge, assessed as MIB1 proliferation index and thymidine phosphorylase (TP) expression. Results were related to vascular density and certain properties of invading cancer cells-MIB1 proliferation activity, TP expression, expression of endogenous markers of hypoxia (hypoxia inducible factor-1 $\alpha ; \mathrm{HIF} 1 \alpha$ ) and acidity (lactate dehydrogenase-5; LDH5). Standard immunohistochemical techniques were applied to 150 colorectal adenocarcinomas.

Results: Normal fibroblasts at the tumour edge had a median MIB1 index of $2 \%$ - significantly higher than normal submucosal fibroblasts $(0.3 \%)$ and significantly lower than cancer cells $(40 \%)$. Normal peritumorous fibroblasts with a proliferation rate above the median strongly expressed TP and were supported by an increased vascular network. Cancer cells close to these fibroblasts had a high MIB1 proliferative index, high HIFl $\alpha$ and LDH5 reactivity, and a clear trend to extramural extension. All associations were significant.

Conclusions: These results suggest that activated fibroblastic status at the invading tumour front sets the stage for stromatogenesis and new blood vessel formation, facilitating deep transmural invasion in colorectal adenocarcinomas. This complicity of peritumorous fibroblasts in the overall aggressiveness/ invasive and metastatic ability of colorectal tumours, occurring within the framework of cancer-stromal cell interactions, is probably favoured by the altered microenvironmental conditions of hypoxia and acidity.
\end{abstract}

$\mathrm{T}$ he formation of new stroma at sites of active tumour cell invasion is a common event in human malignancy. We proposed the term "stromatogenesis" to denote the laying down of a specific stroma, after the proliferation of peritumorous fibroblasts and the disruption of normal tissue continuity facilitating tumour cell invasion. ${ }^{1}$ It does not refer to usual fibrosis, which is generally thought to oppose tumour cell infiltration. This was acknowledged by the inspired work of many investigators who, simulating the conditions of invasion and metastasis, brought epithelial tumour cells into contact with normal fibroblasts in tissue cultures. In all cases, the presence of tumour associated, but not other, fibroblasts accelerated tumour growth. Thus, Fromigue et al reported a cascade of modulated genes encoding proteins involved in growth, angiogenesis, and invasion in normal lung fibroblasts, after coculture with tumour cells of primary non-small cell lung carcinomas. ${ }^{2}$ Nakagawa et al found activation of approximately 170 of 22000 genes in fibroblasts associated with metastatic colon cancer, including many genes encoding growth factors and cell adhesion molecules, ${ }^{3}$ whereas normal skin fibroblasts, not confronting tumour cells, remained inactive.

"The purpose of our study was to investigate the role of proliferating fibroblasts at the invading tumour front of colorectal adenocarcinomas in relation to tumour aggressiveness/invasiveness and metastatic ability"
It is probable that at the edge of the tumour important interactions occur between cancer cells, endothelial cells, and the tumour supporting stroma. ${ }^{4}$ The peritumorous fibroblasts, apparently stimulated by the invading tumour cells, may assume a synergic role in tumour growth, producing factors stimulating cancer cell proliferation and invasion. At the same time, cancer cells induce fibroblastic and endothelial cell activation, leading to stromatogenesis and new blood vessel formation..$^{5-10}$ Yet, the most crucial questions remain: which factors stimulate fibroblastic proliferation? What is the precise role of stromatogenesis in tumour growth and invasion? What is the clinical relevance of such a process?

The purpose of our study was to investigate the role of proliferating fibroblasts at the invading tumour front of colorectal adenocarcinomas in relation to tumour aggressiveness/invasiveness and metastatic ability. Fibroblastic activation/proliferation is an important feature of stromatogenesis, and assessment of the MIBl proliferation index in fibroblasts would provide a quantitative measure of the stromatogenic process. Variations in the rate of fibroblastic proliferation among tumours were also assessed and correlated with histopathological features, cancer metastatic ability, angiogenesis, and angiogenic factors (vascular endothelial growth factor; VEGF), endogenous markers of hypoxia (hypoxia

Abbreviations: $\mathrm{HIF} 1 \alpha$, hypoxia inducible factor- $1 \alpha$; $\mathrm{LDH} 5$, lactate dehydrogenase-5; TP, thymidine phosphorylase; VD, vascular density; VEGF, vascular endothelial growth factor 
Table 1 Details of the antibodies, dilutions, and antigen retrieval methods used

\begin{tabular}{|c|c|c|c|c|}
\hline Primary antibody & Dilution/incubation time & Antigen retrieval & Specificity & Source \\
\hline $\begin{array}{l}\text { Ki-67 } \\
\text { P-GF.44C } \\
\text { VG1 } \\
\text { JC70 (CD31) } \\
\text { ESEE } 122 \\
9002\end{array}$ & $\begin{array}{l}1 / 75\left(75 \mathrm{~min}^{*}\right) \\
1 / 4\left(75 \mathrm{~min}^{*}\right) \\
1 / 4\left(75 \mathrm{~min}^{*}\right) \\
1 / 20\left(30 \mathrm{~min}^{*}\right) \\
1 / 20 \text { (overnight) } \\
1 / 100\left(75 \mathrm{~min}^{*}\right)\end{array}$ & $\begin{array}{l}\mathrm{MW} \dagger \\
\mathrm{MW}+ \\
\mathrm{MW} \dagger \\
\text { Protease‡ } \\
\mathrm{MW} \dagger \\
\mathrm{MW}+\end{array}$ & $\begin{array}{l}\text { MIB1 } \\
\text { TP } \\
\text { VEGF } \\
\text { Endothelium } \\
\text { HIF1 } \alpha \\
\text { LDH5 }\end{array}$ & $\begin{array}{l}\text { YLEM, Avezzano, Italy } \\
\text { Oxford University, Oxford, UK } \\
\text { Oxford University } \\
\text { Dako, Glostrup, Denmark } \\
\text { Oxford University } \\
\text { Abcam, Cambridge, UK }\end{array}$ \\
\hline
\end{tabular}

inducible factor- $1 \alpha$; HIF $1 \alpha$ ), acidity (lactate dehydrogenase5; LDH5), and cellular oxidative stress (thymidine phosphorylase; TP).

\section{MATERIALS AND METHODS}

The material was retrieved from the files of the department of pathology, Democritus University of Thrace Medical School, Alexandroupolis, Greece. Haematoxylin and eosin stained sections were reviewed and the most representative blocks of specimens exhibiting a clear invading tumour front, free of an inflammatory response, were selected. One hundred and fifty consecutive primary colorectal adenocarcinomas were selected. Approval had been obtained by the local research committee. The histological diagnosis, tumour differentiation, depth of local invasion, and lymph node metastasis were reaffirmed. In addition, 20 normal large intestinal samples were included as controls for assessing MIBI proliferation activity in normal submucosal fibroblasts. Normal mucosal fibroblasts were not estimated in our study because of continuous replication and replacement of those lost through differentiation and subsequent desquamation. In 17 of 150 cases, metastasis to distant organs was present and surgery was performed mainly for palliative reasons. The tissues had been routinely fixed and processed.

\section{Immunohistochemistry}

Immunohistochemistry was performed to understand some facets of tumour-stroma interactions. To this end, sections were cut at $3 \mu \mathrm{m}$ and stained with the following immunohistochemical techniques: a standard streptavidin-biotin method for MIB-l, TP, VEGF, HIFl $\alpha$, and LDH5. ${ }^{11-15}$ Antigen retrieval was achieved by microwave heating or enzyme digestion. Antibody reactivity was detected with diaminobenzidine as chromogen. The slides were counterstained with Mayer's haematoxylin. The alkaline phosphatase-anti-alkaline phosphatase method and the JC70/antiCD31 monoclonal antibody were used for endothelial cells to highlight blood vessels. ${ }^{16}$ Table 1 provides details of the primary antibodies used, the working dilutions, etc. Appropriate positive controls were included in each staining run. Non-specific sheep immunoglobulin IgG for LDH5 and mouse IgG for all other antibodies was substituted for the primary antibody as negative control, at a concentration where immunostaining of control slides gave a faint cytoplasmic staining.

\section{Assessment of immunohistochemical results}

Immunohistochemical assessment was performed independently by two observers (AG, ES) all along the invading tumour front. MIBl stained sections were assessed using a $\times 40$ objective and a semiquantitative method. The percentage of TP, VEGF, HIFl $\alpha$, and LDH positive cells was assessed using a $\times 20$ objective. Discrepancies were resolved over a double headed microscope.

MIBI is an antigen expressed in proliferating cells. The expression is nuclear. The proliferative activities of both
Table 2 HIFl $\alpha$ and LDH5 grading system based on the intensity and extent of cytoplasmic and nuclear staining

\begin{tabular}{ll}
\hline HIF $1 \alpha /$ LDH5 grading system & Score \\
\hline $\begin{array}{l}\text { Complete absence of reactivity } \\
\text { Weak cytoplasmic reactivity } \\
\text { (regardless of extent) }\end{array}$ & $\begin{array}{l}\text { Negative (low) } \\
\text { Low }\end{array}$ \\
$\begin{array}{l}\text { Strong cytoplasmic reactivity in } \\
\text { less than } 50 \% \text { of tumour cells }\end{array}$ & Low \\
$\begin{array}{l}\text { Nuclear expression in sporadic } \\
\text { tumour cells }(<10 \% \text { of cells) }\end{array}$ & Low \\
$\begin{array}{l}\text { Strong cytoplasmic expression in } \\
\text { more than } 50 \% \text { of tumour cells }\end{array}$ & High \\
$\begin{array}{l}\text { Nuclear expression in more than } \\
10 \% \text { of tumour cells }\end{array}$ & High \\
\hline HIF $1 \alpha$, hypoxia inducible factor- $1 \alpha ;$ LDH5, lactate dehydrogenase- 5. \\
\hline
\end{tabular}

fibroblasts and tumour cells were evaluated. Ten fields were examined for each tumour. The MIBl proliferating index was estimated as the percentage of fibroblasts or tumour cells with positive nuclei: positive fibroblasts/total fibroblasts and positive tumour cells/total tumour cells, respectively. The median value was used to divide colorectal tumours into groups of low and high MIBl proliferation activity (index).

$\mathrm{TP}$ is an angiogenic factor and a marker of oxidative stress. ${ }^{17}$ TP expression is nuclear and cytoplasmic and was evaluated in both fibroblasts and tumour cells. TP reactivity in $<50 \%$ of fibroblasts or tumour cells was graded as low, whereas expression in more than $50 \%$ of cells was graded as high.

VEGF is another, probably more potent, angiogenic factor. VEGF was assessed in tumour cells. The expression is cytoplasmic. The percentage of VEGF positive cancer cells was assessed semiquantitatively using a $\times 20$ objective. The median value was used as a cutoff point to define cases of high and low VEGF reactivity.

Angiogenesis was assessed in three areas of high vascular density (VD) at $20 \times 10$ magnification. The mean value of each section was recorded. The median VD was used as a cutoff point to define tumours of high and low angiogenic activity.

HIF $1 \alpha$ and LDH5 are endogenous markers of hypoxia and acidity, respectively. Expression is nuclear and cytoplasmic, and was estimated separately. The importance of assessing both cytoplasmic and nuclear staining for HIF expression has been raised in earlier studies. ${ }^{12} 1819$ Although it is generally assumed that nuclear HIF is the active form, HIF protein is synthesised and degraded in the cytoplasm. It is possible that redistribution may occur during tissue collection, but this would be extremely difficult to be controlled; however, the overall expression indicates selective upregulation of the pathway in cancer. Analysis based on pure nuclear expression showed absence of or a very marginally significant association with other molecular factors or prognosis in several previous studies, indicating that it is the tumour specific 
Table 3 Immunohistochemical results (reactivity range, median value, and grouping of cases)

\begin{tabular}{|c|c|c|c|c|}
\hline Invading tumour front & Range & Median & High & Low \\
\hline MIBI index in fibroblasts & $0-20 \%$ & $2 \%$ & 72 & 78 \\
\hline MIBI index in cancer cells & $2-90 \%$ & $40 \%$ & 64 & 86 \\
\hline TP expressing fibroblasts & $0-100 \%$ & $50 \%$ & 80 & 70 \\
\hline TP expressing cancer cells & $0-100 \%$ & $0 \%$ & 8 & 142 \\
\hline VEGF expressing cancer cells & $0-90 \%$ & $10 \%$ & 44 & 106 \\
\hline Vascular density & $15-110$ & 42 & 74 & 76 \\
\hline HIF $1 \alpha$ expressing cancer cells nuc/cyt (grading scale) & & & 58 & 92 \\
\hline HIFl $\alpha$ nuc & $0-30 \%$ & $0 \%$ & & \\
\hline HIFl $\alpha$ cyt & $0-100 \%$ & $5 \%$ & & \\
\hline LDH5 expressing cancer cells nuc/cyt (grading scale) & & & 103 & 47 \\
\hline LDH5 nuc & $0-70 \%$ & $0 \%$ & & \\
\hline LDH5 cyt & $0-100 \%$ & $30 \%$ & & \\
\hline
\end{tabular}

cyt, cyłoplasmic staining; HIF $1 \alpha$, hypoxia inducible factor-1 $\alpha$; LDH5, lactate dehydrogenase-5; nuc, nuclear staining; TP, thymidine phosphorylase; VEGF, vascular endothelial growth factor.

finding of strong cytoplasmic HIF expression that better reflects the HIF upregulated pathway in paraffin wax embedded material. This is in general accordance with the scoring system reported by Zhong et al, ${ }^{19}$ and formed the basis for a grading system (table 2) proposed and applied by our group in a series of previous studies. ${ }^{18}{ }^{20-23}$ The same system was used in the current work to assign colorectal tumours into high and low HIFl $\alpha$ and LDH5 reactivity groups, respectively.

\section{Statistical analysis}

Statistical analysis was performed using the GraphPad Prism 2.01 package (GraphPad, San Diego, California, USA). Fisher's exact test was used for testing relations between categorical variables as appropriate. A p value $\leqslant 0.05$ was considered significant.

\section{RESULTS}

Table 3 shows the immunohistochemical results, as assessed all along the invading tumour front in 150 colorectal adenocarcinomas. There was excellent interobserver agreement in the evaluation of the MIBl score $\left(r^{2}=0.94\right.$; $\mathrm{p}<0.0001)$.

Normal fibroblasts at the tumour edge showed a median MIBl index of 2\% (fig 1), significantly more than the $0.3 \%$ (range, $0.1-0.5 \%$ ) growth fraction found in normal control submucosal fibroblasts. The median MIBI proliferation index

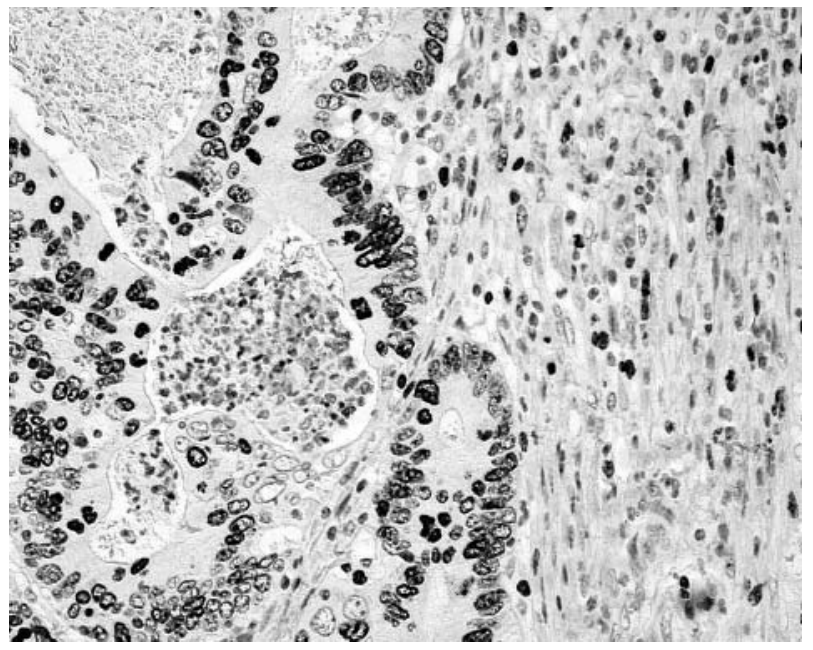

Figure 1 Fibroblasts at the invading tumour edge with high MIB1 proliferative activity. in cancer cells at the tumour-stromal cell interphase was $40 \%$.

TP reactivity in $>50 \%$ of cells was common in host peritumorous fibroblasts (fig 2), but not in cancer cells, where it occurred in only eight of 150 cases.

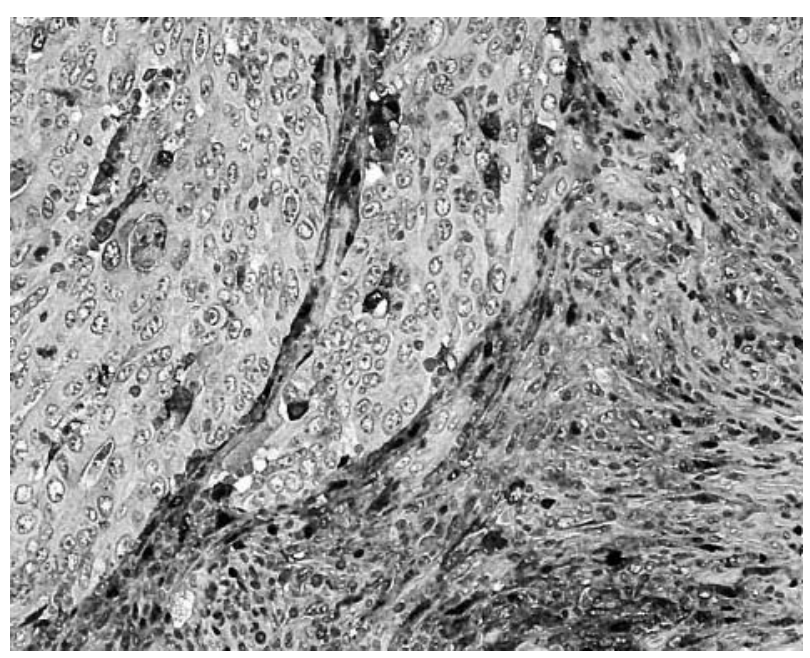

Figure 2 Fibroblasts at the invading tumour edge showing high nuclear/cytoplasmic thymidine phosphorylase expression.

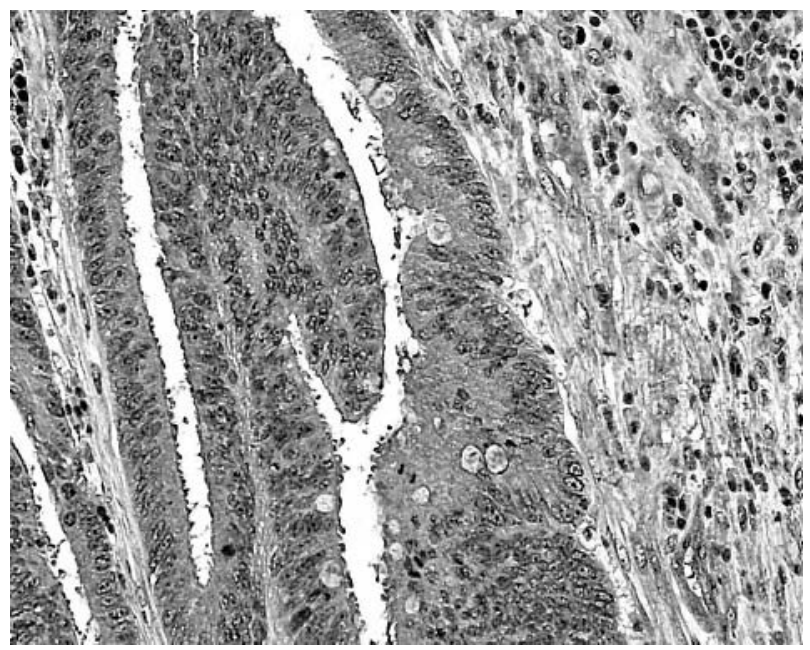

Figure 3 Cytoplasmic and nuclear expression of hypoxia inducible factor-1 $\alpha$ in cancer cells at the invading tumour edge. 


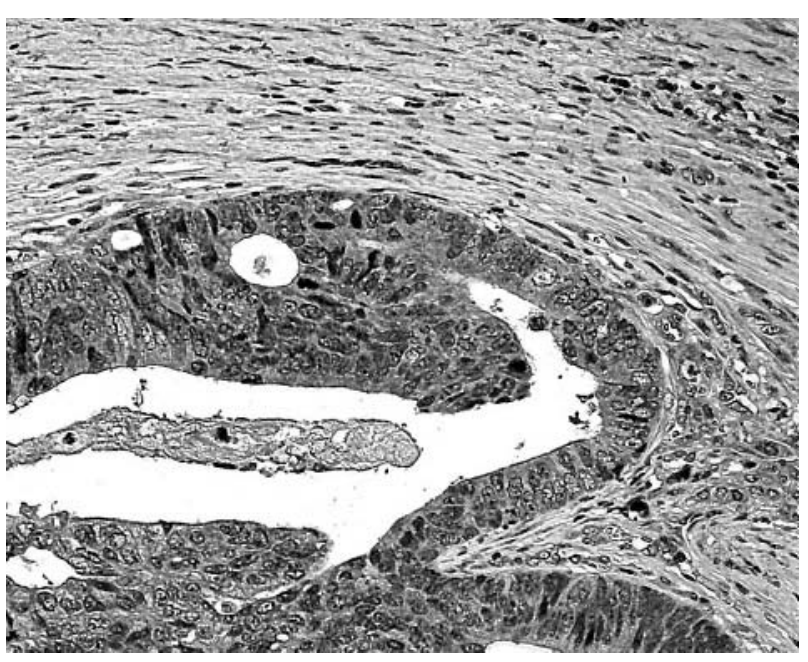

Figure 4 Cytoplasmic expression of vascular endothelial growth factor in cancer cells at the invading tumour edge.

HIF $1 \alpha$ reactivity (fig 3 ) was seen in a median of $5 \%$ of cells, and for LDH5 this figure was 30\%.

Between $0 \%$ and $90 \%$ of cancer cells expressed VEGF (fig 4), with a median value of $10 \%$.

The VD ranged from 15-110, with a median value of 42 .

\section{MIB 1 fibroblastic activity in association with other parameters}

Fibroblasts with a high MIBl proliferation index at the invading tumour edge were associated with high TP reactivity and increased VD at this site (table 4). There was a significant correlation between high fibroblastic growth fraction, as assessed by MIBl immunostaining, and high MIBl index in cancer cells. A positive correlation was also established between MIBI fibroblastic proliferation and deep transmural invasion with extension to the pericolic fat. No association was noted between MIBl index and tumour dimension or anatomical location (table 5).

Furthermore, peritumorous fibroblasts with a high MIBI index most often expressed the endogenous markers of hypoxia (HIFl $\alpha$ ) and intratumoral acidity (LDH5) (table 6). Their association with the angiogenic protein VEGF was only marginal.

There was no association between MIBl proliferation index in peritumorous fibroblasts and lymph node or distant metastasis.

\section{DISCUSSION}

Stromatogenesis is the formation of new stroma occurring, in parallel with the neoplastic process, at sites of active tumour invasion-that is, at the free surface of a developing

Table 4 MIB1 proliferation index in fibroblasts at the invading tumour front and its association with stromal angiogenesis

\begin{tabular}{llll}
\hline & \multicolumn{3}{l}{ MIB1 proliferation index in fibroblasts } \\
\cline { 2 - 4 } & Low & High & p Value \\
\hline $\begin{array}{l}\text { TP in fibroblasts } \\
\text { Low } \\
\text { High }\end{array}$ & 46 & 24 & 0.001 \\
VD & 32 & 48 & \\
Low & 46 & 30 & 0.04 \\
High & 32 & 42 & \\
\hline TP, thymidine phosphorylase; VD, vascular density. & \\
\hline
\end{tabular}

Table 5 MIB1 proliferation index in fibroblasts at the invading tumour front and its association with primary tumour characteristics

\begin{tabular}{llll}
\hline & \multicolumn{3}{l}{ MIB 1 proliferation index in fibroblasts } \\
\cline { 2 - 4 } & Low & High & p Value \\
\hline $\begin{array}{l}\text { MIB1 cancer cells } \\
\text { Low }\end{array}$ & 60 & 26 & $<0.0001$ \\
$\quad$ High & 18 & 46 & \\
$\begin{array}{l}\text { Tumour dimensions } \\
\quad \leqslant 4 \mathrm{~cm}\end{array}$ & 32 & 29 & 0.49 \\
$>4 \mathrm{~cm}$ & 36 & 43 & \\
Location & & \\
Rectum & & & \\
Sigmoid & 22 & 18 & \\
$\quad$ Colon & 20 & 16 & 0.65 \\
Transmural invasion & 36 & 38 & \\
$\quad$ No & 36 & 22 & 0.05 \\
Yes & 42 & 50 & \\
\hline
\end{tabular}

Table 6 MIB1 proliferation index in fibroblast at the invading tumour front and its association with parameters indicative of hypoxic stress and acidity

\begin{tabular}{cccc}
\hline & \multicolumn{3}{l}{ MIB1 proliferation index in fibroblasts } \\
\cline { 2 - 4 } & Low & High & p Value \\
\hline $\begin{array}{c}\text { VEGF } \\
\text { Low }\end{array}$ & 60 & 46 & 0.07 \\
High & 18 & 26 & \\
HIF1 $\alpha$ & & & \\
Low & 56 & 36 & 0.006 \\
High & 22 & 36 & \\
LDH5 & 30 & 17 & 0.05 \\
Low & 48 & 55 & \\
High & & & \\
\hline
\end{tabular}

HIF $1 \alpha$, hypoxia inducible factor- $1 \alpha ; L D H$, lactate dehydrogenase; VEGF, vascular endothelial growth factor.

exophytic tumour, at the invading tumour front of an advancing endophytic tumour, and at sites of tumour metastasis, wherein the newly formed stroma disrupts the continuity of normal structures, cleaving pathways for the invading tumour cells. Stromatogenesis is of utmost importance for tumour growth and progression, with the new stroma sustaining the invading tumour cells and giving grounds for angiogenesis. The newly formed tumour associated spindle cells are qualitatively altered, having an activated gene profile compared with normal non-activated fibroblasts ${ }^{2}$ and also (as was shown immunohistochemically in our study) expressing $\alpha$ smooth muscle actin, but not vimentin or desmin (data not shown), suggesting a shift to myofibroblastic differentiation. This is in accordance with a recent report of ours. ${ }^{1}$

Stromatogenesis occurs in almost all types of invading tumours, and some form of quantitation would be useful in assessing tumour aggressiveness. Perhaps the enumeration of spindle cells in a substratum harbouring tumour cells (rate of fibroblast proliferation) may prove effective. In our study, there was increased MIBI proliferative activity in the host fibroblasts at the invading tumour edge compared with the very low, almost negligible, proliferation of fibroblasts in normal colonic submucosa. The reason for this accelerated proliferative activity should be sought in tumour-stroma interactions. For example, the secretion of fibronectin, vitronectin, and other soluble factors from colonic cancer cells induces new stroma formation through activation, migration, and proliferation of host fibroblasts. ${ }^{24}{ }^{25}$ The loss 
of responsiveness to transforming growth factor $\beta$ in mouse fibroblasts results in the development of invasive carcinoma in parallel with the production of abundant stroma. ${ }^{26}$

We also found that the increased proliferation rate in the peritumorous fibroblasts was accompanied by an analogous, or rather exaggerated, increase in MIBl activity (index) in cancer cells. This is in accordance with kinetic studies, exploiting coculture models of cancer cells and normal tumour confronting fibroblasts, but not other normal fibroblasts. In such cultures, Hauptmann et al demonstrated proliferative activity in both colonic fibroblasts and colorectal cancer cells. ${ }^{27}$ Camps et al succeeded in accelerating growth in human epithelial tumours after coinoculation of cancer cells with transformed fibroblasts in athymic mice. ${ }^{28}$ Olumi et al stimulated tumour growth and progression in initiated prostate epithelial cells after they were cocultured with tumour associated prostatic fibroblasts. ${ }^{29}$ Shekhar et al indicated that tumour affiliated breast fibroblasts induce the proliferation of cancer cells and ductal alveolar morphogenesis in cocultures with breast cancer cells. ${ }^{30}$ This was further augmented in the presence of active angiogenesis. ${ }^{30}$

\section{"The altered physiological conditions of hypoxia and acidity may contribute to the activation of peritumorous fibroblasts, enhancing further tumour aggressiveness"}

In agreement, we found that the highly activated status of the tumour confronting fibroblasts and the fibroblast confronting tumour cells, assessed by MIBI proliferation index along the invading tumour front, was associated with deep transmural cancer cell invasion in the presence of TP and increased angiogenesis. TP overexpression is an endogenous marker of oxidative stress, promoting thymidine catabolism to 2-deoxy-D-ribose-1-phosphate, a strongly reducing sugar that generates radical oxygen species during protein glycation. ${ }^{17}{ }^{31}$ Under such stress conditions, tumour cells secrete the angiogenic factors VEGF and interleukin 8, together with matrix metalloproteinases. ${ }^{17}$ This would explain why TP expressing fibroblasts may promote angiogenesis, invasion, and metastasis, as was confirmed in several clinicopathological studies. ${ }^{23}{ }^{32-34}$ Along these lines, it was also shown that cell-cell contact between cancer cells and tumour supporting fibroblasts enhanced the production and activation of matrix metalloproteinases by cancer cells, promoting pericellular proteolysis, angiogenesis, and tumour cell invasion. ${ }^{35}{ }^{36}$ Similarly, in the previously cited study of Shekhar et $a l^{30}$ the inductive morphogenic effects of tumour associated fibroblasts was further augmented by the inclusion of endothelial cells with a dramatic increase in proliferation of duct and acini, which was accompanied by increased expression of matrix metalloproteinases, degradation of the extracellular matrix, and, finally, tumour cell invasion. ${ }^{30}$ Others have suggested that the stimulatory effect of peritumorous fibroblasts on cancer cell migration is probably mediated through the secretion of a "migration stimulating factor", which has been effectively shown in skin fibroblasts from patients with breast cancer, ${ }^{37}$ or through the expression of integrin chains in tumour cells to promote fibronectin mediated tumour cell invasion. ${ }^{38}$ Although an association between increased proliferation of host fibroblasts at the invading tumour edge and metastasis either to lymph nodes or distant organs was not confirmed in our present study, this does not preclude a complementary role for activated fibroblasts in the metastatic process, perhaps through an individual cancer cell genotype or activated angiogenesis.

Another, equally, important observation of our study was the direct association between increased fibroblastic proliferation and overexpression of HIFl $\alpha$ and its downstream
Take home messages

- In colorectal adenocarcinomas, the high proliferation index and expression of thymidine phosphorylase in host fibroblasts at the invading tumour edge suggest that the activation of fibroblasts at this site sets the stage for stromatogenesis and new blood vessel formation, facilitating deep transmural invasion

- The involvement of peritumorous fibroblasts in the overall aggressiveness/invasive and metastatic ability of colorectal tumours, via cancer-stromal cell interactions, is probably favoured by the altered microenvironmental conditions of hypoxia and acidity

gene LDH5. Given that HIFl $\alpha$ induction is hypoxia dependent, ${ }^{39}$ such tumours should be hypoxic and, presumably, acidic, mainly because of the biochemical transformation of pyruvate to lactate suggested by the high expression of LDH $5 .^{40}$ The ability of fibroblasts to proliferate under hypoxic conditions has been confirmed experimentally, ${ }^{41}$ and may have an important role in the development of pulmonary hypertension, a condition where hypoxia induces proliferation of adventitial fibroblasts in the pulmonary artery. ${ }^{42} 43$ This is probably because hypoxia increases ATP concentrations in adventitial fibroblasts and endothelial cells, promoting DNA synthesis and proliferation. ${ }^{44}$ Anderson et al showed in normal rat fibroblasts a three stage response to anoxia, consisting of: (a) transcription, (b) induction of several intracellular proteins, and (c) secretion of three major proteins, including the protease cathepsin $\mathrm{L} .{ }^{45}$ What is most interesting is that in the authors' opinion fibroblasts, under anoxic conditions, show several characteristics of malignant cells. The response of fibroblasts to acidic conditions is not well understood. A recent study has reported that lactate increases intracellular oxidants, promoting proliferation of cultured fibroblasts in a dose dependent manner. ${ }^{46}$ Another study showed that platelet induced proliferation of fibroblasts was enhanced at an acidic $\mathrm{pH}$, suggesting an interplay of platelet aggregation and tumour acidity in the induction of fibroblastic growth. ${ }^{47}$

We conclude that host fibroblasts at the invading tumour edge have a high activation status, as suggested by the high proliferation activity and the overexpression of TP. The intensity of this fibroblastic activity is related to stromatogenesis, increased blood vessel formation, and invasion of colorectal cancer cells through the muscle wall into the serosa and the pericolic fat. The close association of proliferative activity of host fibroblasts at the invading tumour edge with endogenous markers of hypoxia and acidity suggest that, apart from the stroma-cancer interactions, the altered physiological conditions of hypoxia and acidity may contribute to the activation of peritumorous fibroblasts, enhancing further tumour aggressiveness.

\section{ACKNOWLEDGEMENTS}

The authors are grateful to Professor KC Gatter, University of Oxford, for kindly providing the HIFl $\alpha$, TP, and VEGF antibodies for immunohistochemistry. The authors wish also to thank Mrs G Kirmizi for excellent technical assistance.

\section{Authors' affiliations}

E Sivridis, A Giatromanolaki, Department of Pathology, Democritus University of Thrace Medical School, Alexandroupolis 68100, Greece M I Koukourakis, Department of Radiotherapy/Oncology, Democritus University of Thrace Medical School 


\section{REFERENCES}

1 Sivridis E, Giatromanolaki A, Koukourakis MI. "Stromatogenesis" and tumor progression. Int I Surg Pathol 2004;12:1-9.

2 Fromigue $\mathrm{O}$, Louis $\mathrm{K}$, Dayem $\mathrm{M}$, et al. Gene expression profiling of normal human pulmonary fibroblasts following coculture with non-small-cell lung cancer cells reveals alterations related to matrix degradation, angiogenesis, cell growth and survival. Oncogene 2003:22:8487-97.

3 Nakagawa H, Liyanarachchi S, Davuluri RV, et al. Role of cancer-associated stromal fibroblasts in metastatic colon cancer to the liver and their expression profiles. Oncogene 2004;23:7366-77.

4 Giatromanolaki A, Sivridis E, Koukourakis MI. Tumour angiogenesis: vascular growth and survival. APMIS 2004:112:431-40.

5 De Wever O, Mareel M. Role of tissue stroma in cancer cell invasion. J Pathol 2003;200:429-47.

6 Almholt K, Johnsen M. Stromal cell involvement in cancer. Recent Results Cancer Res 2003;162:31-42.

7 Mueller MM, Fusenig NE. Tumor-stroma interactions directing phenotype and progression of epithelial skin tumor cells. Differentiation 2002;70:486-97.

8 Cunha GR, Hayward SW, Wang YZ. Role of stroma in carcinogenesis of the prostate. Differentiation 2002;70:473-85.

9 Ruiter D, Bogenrieder T, Elder D, et al. Melanoma-stroma interactions: structural and functional aspects. Lancet Oncol 2002;3:35-43.

10 Schor SL, Schor AM. Phenotypic and genetic alterations in mammary stroma: implications for fumour progression. Breast Cancer Res 2001;3:373-9.

11 McCormick D, Chong H, Hobbs C, et al. Detection of the Ki-67 antigen in fixed and wax-embedded sections with the monoclonal antibody MIBI. Histopathology 1993;22:355-60

12 Talks KL, Turley H, Gatter KC, et al. The expression and distribution of the hypoxia-inducible factors HIF-lalpha and HIF-2alpha in normal human tissues, cancers, and tumor-associated macrophages. Am J Pathol 2000;157:411-21.

13 Turley H, Scott PA, Watts VM, et al. Expression of VEGF in routinely fixed material using a new monoclonal antibody VG1. J Pathol 1998;186:313-18.

14 Fox SB, Westwood M, Moghaddam A, et al. The angiogenic factor plateletderived endothelial cell growth factor/thymidine phosphorylase is upregulated in breast cancer epithelium and endothelium. $\mathrm{Br} J$ Cancer 1996;73:275-80.

15 Koukourakis MI, Giatromanolaki A, Sivridis E. Lactate dehydrogenase isoenzymes 1 and 5: differential expression by neoplastic and stromal cells in non-small cell lung cancer and other epithelial malignant tumors. Tumour Biol 2003;24:199-202.

16 Horak ER, Leek R, Klenk N, et al. Angiogenesis, assessed by platelet/ endothelial cell adhesion molecule antibodies, as indicator of node metastases and survival in breast cancer. Lancet 1992;340:1120-4.

17 Brown NS, Jones A, Fujiyama C, et al. Thymidine phosphorylase induces carcinoma cell oxidative stress and promotes secretion of angiogenic factors. Cancer Res 2000;60:6298-302.

18 Giatromanolaki A, Koukourakis MI, Sivridis E, et al. Relation of hypoxia inducible factor 1 alpha and 2 alpha in operable non-small cell lung cancer to angiogenic/molecular profile of tumours and survival. $\mathrm{Br} J$ Cancer $2001 ; 85: 881-90$

19 Zhong H, De Marzo AM, Laughner E, et al. Overexpression of hypoxiainducible factor lalpha in common human cancers and their metastases. Cancer Res 1999:59:5830-5.

20 Sivridis E, Giatromanolaki A, Gatter KC, Tumor and Angiogenesis Research Group, et al. Association of hypoxia-inducible factors lalpha and 2alpha with activated angiogenic pathways and prognosis in patients with endometrial carcinoma. Cancer 2002;95:1055-63.

21 Koukourakis MI, Giatromanolaki A, Sivridis E, et al. Hypoxia-inducible factor (HIFIA and HIF2A), angiogenesis, and chemoradiotherapy outcome of squamous cell head-and-neck cancer. Int J Radiat Oncol Biol Phys 2002;53:1 192-202.

22 Koukourakis MI, Giatromanolaki A, Skarlatos J, et al. Hypoxia inducible factor (HIF-la and HIF-2a) expression in early esophageal cancer and response to photodynamic therapy and radiotherapy. Cancer Res $2001 ; 61: 1830-2$.

23 Giatromanolaki A, Sivridis E, Kouskoukis C, et al. Hypoxia-inducible factors lalpha and 2alpha are related to vascular endothelial growth factor expression and a poorer prognosis in nodular malignant melanomas of the skin. Melanoma Res 2003;13:493-501.

24 Morimoto $M$, Irimura T. Fibroblast migratory factor derived from mouse colon carcinoma cells: potential roles of fibronectin in tumor stroma formation. J Cell Biochem 2001;80:635-46.
25 Tomasini-Johansson BR, Sundberg C, Lindmark G, et al. Vitronectin in colorectal adenocarcinoma-synthesis by stromal cells in culture. Exp Cell Res 1994;214:303-12.

26 Bhowmick NA, Chytil A, Plieth D, et al. TGF-beta signaling in fibroblasts modulates the oncogenic potential of adjacent epithelia. Science 2004;303:848-51.

27 Hauptmann S, Siegert A, Berger S, et al. Regulation of cell growth and the expression of extracellular matrix proteins in colorectal adenocarcinoma: a fibroblast-tumor cell coculture model to study tumor-host interactions in vitro. Eur J Cell Biol 2003;82:1-8.

28 Camps JL, Chang SM, Hsu TC, et al. Fibroblast-mediated acceleration of human epithelial tumor growth in vivo. Proc Natl Acad Sci U S A 1990;87:75-9.

29 Olumi AF, Grossfeld GD, Hayward SW, et al. Carcinoma-associated fibroblasts direct tumor progression of initiated human prostatic epithelium. Cancer Res 1999;59:5002-11.

30 Shekhar MP, Werdell J, Santner SJ, et al. Breast stroma plays a dominant regulatory role in breast epithelial growth and differentiation: implications for tumor development and progression. Cancer Res 2001;61:1320-6.

31 Sengupta S, Sellers LA, Matheson HB, et al. Thymidine phosphorylase induces angiogenesis in vivo and in vitro: an evaluation of possible mechanisms. Br J Pharmacol 2003;139:219-31.

32 Koukourakis MI, Giatromanolaki A, Kakolyris S, et al. Different patterns of stromal and cancer cell thymidine phosphorylase reactivity in non-small-cell lung cancer: impact on tumour neoangiogenesis and survival. $\mathrm{Br} J$ Cancer 1998:77:1696-703.

33 Sivridis E, Giatromanolaki A, Koukourakis Ml, et al. Thymidine phosphorylase expression in endometrial carcinomas. Clin Exp Metastasis 1999;17:445-50

34 Sivridis E, Giatromanolaki A, Papadopoulos I, et al. Thymidine phosphorylase expression in normal, hyperplastic and neoplastic prostates: correlation with tumour associated macrophages, infiltrating lymphocytes, and angiogenesis. $\mathrm{Br} J$ Cancer 2002;86:1465-71.

35 Sato T, Sakai T, Noguchi Y, et al. Tumor-stromal cell contact promotes invasion of human uterine cervical carcinoma cells by augmenting the expression and activation of stromal matrix metalloproteinases. Gynecol Oncol 2004;92:47-56.

36 Behrens $\mathbf{P}$, Rothe $M$, Wellmann $A$, et al. The Ets- 1 transcription factor is up regulated together with MMP 1 and MMP 9 in the stroma of pre-invasive breast cancer. J Pathol 2001;194:43-50.

37 Grey AM, Schor AM, Rushton G, et al. Purification of the migration stimulating factor produced by fetal and breast cancer patient fibroblasts. Proc Natl Acad Sci U S A 1989:86:2438-42.

38 Neijari M, Anderson W, Pourreyron C, et al. The role of fibroblasts in the modulation of integrin-dependent interactions between the gastric cell line HGT-1 and fibronectin. Int J Cancer 2004;112:560-9.

39 Semenza GL. Hydroxylation of HIF-1: oxygen sensing at the molecular level. Physiology Bethesda 2004;19:176-82.

40 Yamagata M, Hasuda K, Stamato T, et al. The contribution of lactic acid to acidification of tumours: studies of variant cells lacking lactate dehydrogenase. $\mathrm{Br} J$ Cancer 1998;77:1726-31.

41 Gardner LB, Li F, Yang X, et al. Anoxic fibroblasts activate a replication checkpoint that is bypassed by Ela. Mol Cell Biol 2003;23:9032-45

42 Gerasimovskaya EV, Tucker DA, Stenmark KR. Activation of phosphatidylinositol 3-kinase, Akt and mammalian target of rapamycin (mTOR) is necessary for hypoxia-induced pulmonary artery adventitial fibroblast proliferation. J Appl Physiol 2005;98:722-31.

43 Banks MF, Gerasimovskaya EV, Tucker DA, et al. Egr-1 antisense oligonucleotides inhibit hypoxia-induced proliferation of pulmonary artery adventitial fibroblasts. J Appl Physiol 2005;98:732-8.

44 Gerasimovskaya EV, Ahmad S, White CW, et al. Extracellular ATP is an autocrine/paracrine regulator of hypoxia-induced adventitial fibroblast growth. Signaling through extracellular signal-regulated kinase- $1 / 2$ and the Egr-1 transcription factor. J Biol Chem 2002;277:44638-50.

45 Anderson GR, Stoler DL, Scarcello LA. Normal fibroblasts responding to anoxia exhibit features of the malignant phenotype. J Biol Chem 1989:264:14885-92.

46 Wagner S, Hussain MZ, Hunt TK, et al. Stimulation of fibroblast proliferation by lactate-mediated oxidants. Wound Repair Regen 2004;12:368-73.

47 Liu Y, Kalen A, Risto O, et al. Fibroblast proliferation due to exposure to a platelet concentrate in vitro is $\mathrm{pH}$ dependent. Wound Repair Regen 2002; 10:336-40 